\title{
Monitoring and Analysis of Sand Dune Movement and Growth on the Navajo Nation, Southwestern United States
}

\author{
ecurring drought and rising \\ temperatures have caused \\ reactivation and renewed growth of \\ sand dunes on the lands of the Navajo \\ Nation on the Colorado Plateau. \\ Migrating dunes threaten health, \\ housing, and transportation pathways. \\ U.S. Geological Survey (USGS) \\ scientists are conducting research \\ to better understand the processes \\ of dune growth and movement. This \\ research will provide critical data to \\ the Native peoples of the region in their \\ response to the changing environment.
}

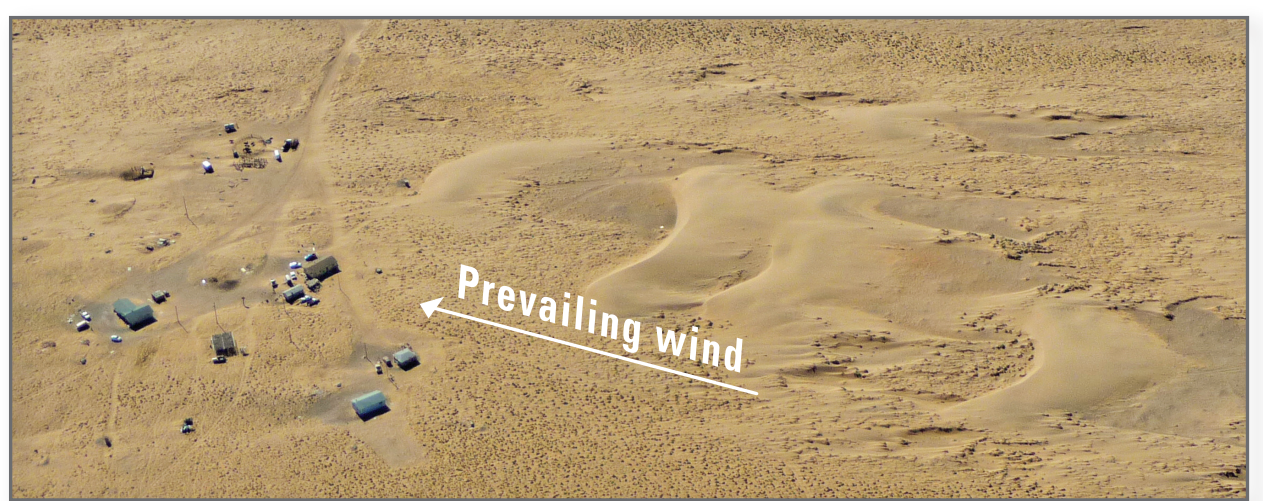

An increasingly dry climate in the U.S. Southwest has led to accelerated migration of active sand dunes and reactivation of previously inactive dunes. In the Native lands of the Colorado Plateau, sand dunes and sand sheets cover one-third of the area. Migration of these dunes can threaten housing and roads, as at this Navajo settlement. Dominant wind direction (arrow) is to the northeast. (USGS photo by Jon Mason.)

\section{Introduction}

The Native Navajo people of the southwestern United States are currently challenged by an increasingly dry climate. Increased aridity from warmer temperatures, combined with recurring drought, has resulted in a large amount of migrating sand that threatens housing, health, and transportation. More than one-third of Native lands on the Colorado Plateau (Navajo Nation and Hopi Tribal Lands) are covered with sand dunes and sand sheets. Such dunes and sand sheets are common features of arid and semiarid environments across the globe, where specific conditions of abundant sand supply, wind, and minimum vegetation cover promote their occurrence. Existing dunes can be grouped into three climatic threshold classes (Lancaster, 1988): immobile (fully stabilized by vegetation), partly active (exposed dune crests with some vegetation cover), and fully active (wind-driven with no vegetation cover).

U.S. Geological Survey (USGS) scientists are conducting research with the aim of providing critical data to the Native peoples of the region in response to growing dune activity, diminished vegetation cover, and an increasingly arid environment (Redsteer, 2002). The USGS interdisciplinary studies are focused on understanding the processes responsible for initiation of eolian (windblown) sand movement, including the influence of source sediment availability, climate, vegetation, and land use. Reactivation of inactive dunes could have serious consequences on human and animal

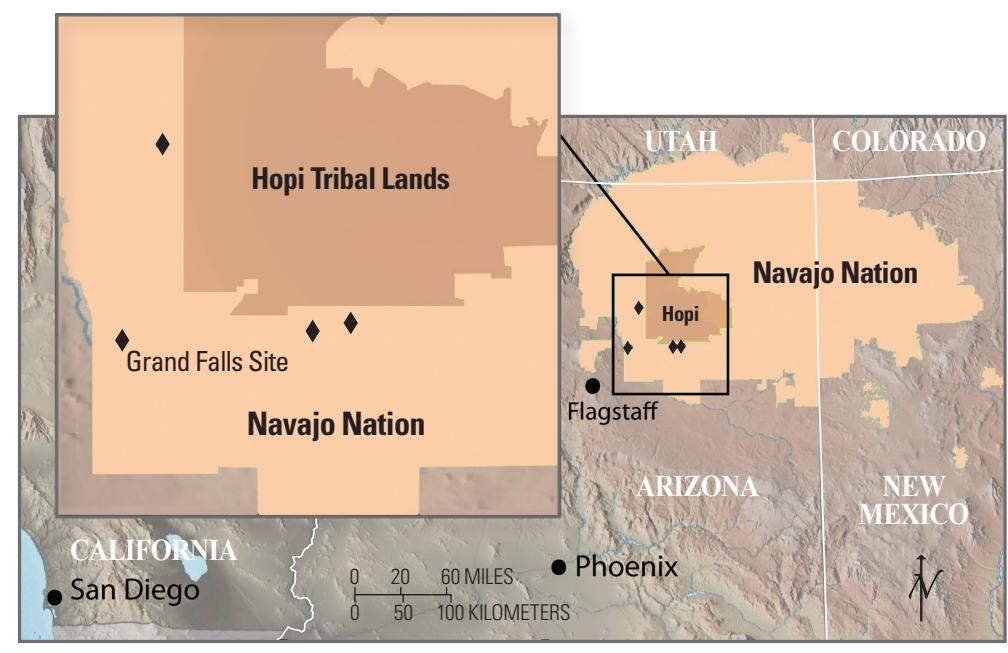

U.S. Department of the Interior U.S. Geological Survey populations, agriculture, grazing, and infrastructure on the Navajo Nation and similar areas of the Southwest. Annual rainfall in the western Navajo Nation has fallen below 3 inches $(75 \mathrm{~mm})$ during the most recent drought (Redsteer and others, 2010). As a result, the areal extent of sand susceptible to mobilization has increased significantly. Moreover, regionally significant sand and dust storms are becoming commonplace during the spring, which is typically dry and windy.

\section{Methods and Results}

Monitoring efforts to measure rates of dune movement and growth in active dune fields are accomplished through a number of methods. The migration of dunes is measured by combining surficial mapping with aerial and satellite imagery, GPS (global positioning system), and ground-based lidar (light detection and ranging) measurements. Rates of dune movement and the incidence of accompanying dust storms are compared to meteorological conditions measured at established monitoring sites. An historical survey of available aerial and satellite imagery, with resolutions of 3.3 feet $(1 \mathrm{~m})$ per pixel or better, has been compiled for the dune field studied. The compiled imagery spans the lifetime of the dune field, from before its appearance in the mid 1950s until 2010. In each image, the leading edge of the active dune field was identified and delineated, local communities. 


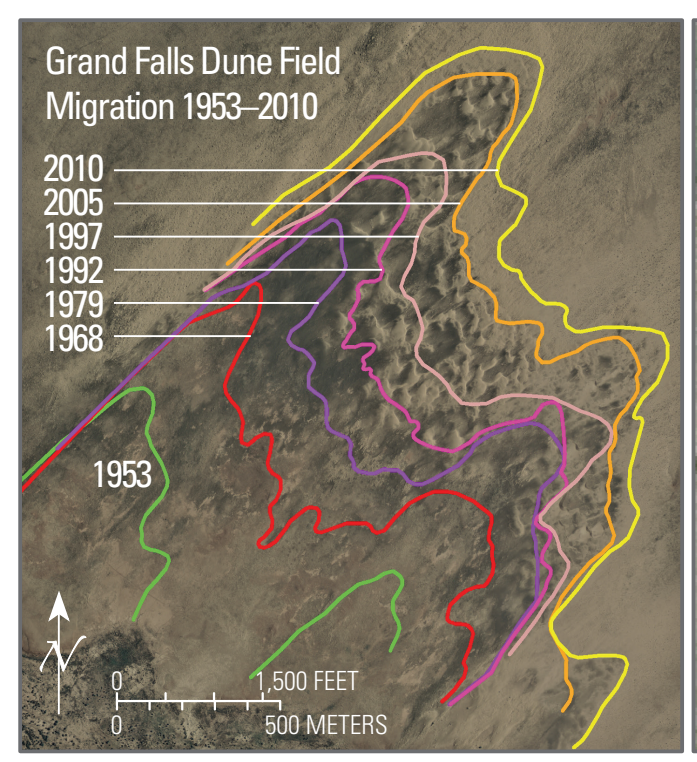

facilitating calculations of the areal extent and migration-rate changes for the dune field over the past 60 years.

Survey-grade GPS instruments allow the mapping and monitoring of dune slip faces to within 4 inches $(10 \mathrm{~cm})$ while also providing great flexibility in timing data-collection efforts. The ground-based lidar was used to record volumetric changes in two individual dunes within the Grand Falls monitoring site (see map). The lidar instrument collects data at six locations surrounding each dune, recording millions of relative point locations in three dimensions during its scans. These data allow the creation of highly detailed spatial models of the dunes. Repeat scans, before and after the winter/spring windy season, help in understanding the geomorphic changes of the dunes as they move across the landscape.

Measurements of dune migration are accompanied by meteorological monitoring to understand conditions that contribute to differing rates of sand transport and dune movement. The Grand Falls monitoring station is equipped with a precipitation gage, a temperature probe, soil moisture probe, and anemometers at the upwind and downwind portions of the dune field that measure wind direction and speed. It also has a digital camera that captures images when wind speeds exceed 10 miles per hour $(15 \mathrm{~km} / \mathrm{hr})$, providing visual evidence of sediment movement across the surface during windstorms and information on visibility during dust storms. These data are being used to evaluate how weather fluctuations contribute to changes in dune shape, size, and migration rates, and under what conditions sand storms are accompanied by dust transport.

The results of this research show that the rate of dune migration in active regions varies from year to year, depending on local

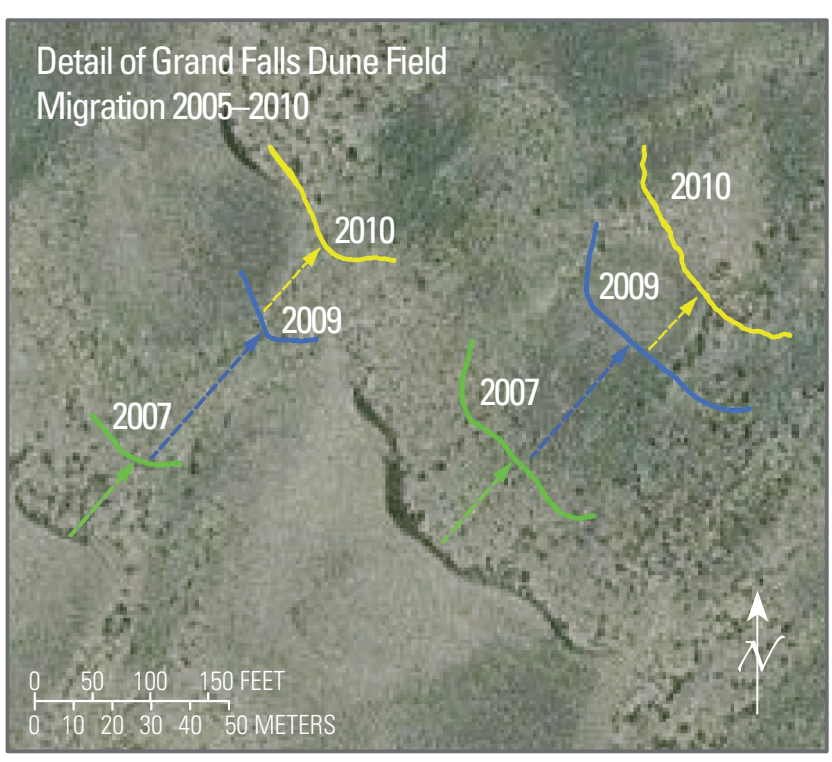

Archival imagery has allowed plotting the migration of the dune field at the Grand Falls site (see map) from 1953 to 2010. Left: Here the dune front at various times is plotted on an image from 2005. The dominant wind direction has been from the southwest (lower left) throughout the time period studied. Right: Enlarged view of a small part of the Grand Falls dune field showing recent (2005 to 2010) migration of dunes plotted on a satellite image taken in 2005. These dunes are migrating at a rapid ratemore than 330 feet $(100 \mathrm{~m})$ in just 5 years. meteorological conditions. In 2009, an unusually windy and dry year, we measured dune migration rates as high as 112-157 feet per year (34 to $48 \mathrm{~m} / \mathrm{yr}$ ), depending on the locality. With current drought conditions and typical springtime winds, dunes in the region of study can move more than 3.3 feet $(1 \mathrm{~m})$ in a single windstorm. The overall size of active dune fields and the overall number of dunes have also changed. Assessment of archived imagery shows that the Grand Falls dune field has grown in areal extent by 70 percent (both laterally and downwind) from 1992 to 2007, a period of only 15 years.

\section{Conclusion}

Initial data from this study indicate that sand-dune migration rates are currently about 115 feet per year $(35 \mathrm{~m} / \mathrm{yr})$ or more in the arid southwestern portion of the Navajo Nation. Fieldwork and data from photo archives show growth of active dune fields and reactivation of formerly stabilized surfaces. The formation and movement of active dunes on the downwind side of stream-bed sand sources is presently endangering housing and transportation, potentially jeopardizing native plants and grazing lands, increasing health hazards to humans and animals, and affecting regional air quality.

A more complete understanding of the complex environmental processes that have such a profound influence on the Navajo Nation requires more detailed datasets. USGS scientists, with the cooperation of Navajo communities, are working to expand the sensor network in the southwestern Navajo Nation and concurrently develop new analysis techniques. The resulting analyses will provide the Navajo people with a deeper understanding of the processes driving dune migration and will help identify possible techniques for mitigating hazards from sand and dust transport.

\section{References}

Lancaster, N., 1988, Development of linear dunes in the southwestern Kalahari, southern Africa: Journal of Arid Environments, v. 14, p. 233-244.

Redsteer, M.H., 2002, Factors effecting dune mobility on the Navajo Nation, Arizona, USA, in 5th International Conference on Aeolian Research and The Global Change \& Terrestrial Ecosystem-Soil Erosion Network, Lubbock Texas, July 22-25, 2002, Proceedings: Lubbock Texas, Texas Tech University, International Center for Arid and Semiarid Lands Studies, Publication number 02-2, p. 385

Redsteer, M.H., Bogle, R., Vogel, J., Block, D., Velasco, M., and Middleton, B., 2010, The history and growth of a recent dune field at Grand Falls, Navajo Nation, NE Arizona [abs.]: Geological Society of America Abstracts with Programs, v. 42, no. 5, p. 416.

\author{
Margaret Hiza Redsteer, \\ Rian C. Bogle, and John M. Vogel \\ Edited by Peter H. Stauffer \\ Layout by Jeanne S. DiLeo
}

The Leupp Chapter of the Navajo Nation passed a resolution in support of this research, and of the monitoring site. Our work has been conducted with the support of the Navajo Nation Department of Water Management, Navajo Nation Historic Preservation Office, and a research permit granted by the

Navajo Nation Department of Minerals. Any persons wishing to conduct geologic investigations on the Navajo Nation must first apply, and receive, a permit from the Navajo Nation Mineral Department, P.O. Box 1910, Window Rock, Arizona 86515, telephone (928) 871-6587.

For more information contact:
Margaret Hiza Redsteer
U.S. Geological Survey, 2255 North Gemini Drive
Flagstaff, AZ 86001
mhiza@usgs.gov
http://geomaps.wr.usgs.gov/navajo/index.htm
http://sgst.wr.usgs.gov/dunes/
This fact sheet and any updates to it are available
online at
http://pubs.usgs.gov/fs/2011/3085/

